\title{
Ephrin-A5 Exerts Positive or Inhibitory Effects on Distinct Subsets of EphA4-Positive Motor Neurons
}

\author{
Johann Eberhart, ${ }^{1}$ Jason Barr, ${ }^{1}$ Sinead 0'Connell, ${ }^{1}$ Alleda Flagg, ${ }^{1}$ Mary E. Swartz, ${ }^{1}$ Karina S. Cramer, ${ }^{2}$ \\ Kathryn W. Tosney, ${ }^{3}$ Elena B. Pasquale, ${ }^{4}$ and Catherine E. Krull ${ }^{1}$ \\ ${ }^{1}$ Division of Biological Sciences, University of Missouri-Columbia, Columbia, Missouri 65211, ${ }^{2}$ Department of Neurobiology and Behavior, University of \\ California-Irvine, Irvine, California 92697, ${ }^{3}$ Departments of Molecular, Cellular, and Developmental Biology, University of Michigan, Ann Arbor, Michigan \\ 48109, and ${ }^{4}$ The Burnham Institute, La Jolla, California 92037
}

Eph receptor tyrosine kinases and ephrins are required for axon patterning and plasticity in the developing nervous system. Typically, Eph-ephrin interactions promote inhibitory events; for example, prohibiting the entry of neural cells into certain embryonic territories. Here, we show that distinct subsets of motor neurons that express EphA4 respond differently to ephrin-A5. EphA4-positive LMC(1) axons avoid entering ephrin-A5-positive hindlimb mesoderm. In contrast, EphA4-positive MMC(m) axons extend through ephrin-A5-positive rostral half-sclerotome. Blocking EphA4 activation in $\mathrm{MMC}(\mathrm{m})$ neurons or expanding the domain of ephrin-A5 expression in the somite results in the aberrant growth of $\mathrm{MMC}(\mathrm{m})$ axons into the caudal half-sclerotome. Moreover, premature expression of EphA4 in $\mathrm{MMC}(\mathrm{m})$ neurons leads to a portion of their axons growing into novel ephrin-A5-positive territories. Together, these results indicate that EphA4ephrin-A5 signaling acts in a positive manner to constrain $\mathrm{MMC}(\mathrm{m})$ axons to the rostral half-sclerotome. Furthermore, we show that Eph activation localizes to distinct subcellular compartments of $\mathrm{LMC}(\mathrm{l})$ and $\mathrm{MMC}(\mathrm{m})$ neurons, consistent with distinct EphA4 signaling cascades in these neuronal subpopulations.

Key words: motor axon; Eph; ephrin; mesoderm; electroporation; chick

\section{Introduction}

Neural circuits that control locomotion are composed of distinct motor neurons that extend their axons precisely to innervate target muscles (Landmesser, 1978). Motor neurons that project to particular muscles are organized into columns in the neural tube, expressing a unique combination of transcription factors (TFs) that likely specifies motor neuron identity (Landmesser, 1978; Tsuchida et al., 1994). The lateral motor column (LMC) forms only at limb levels; the position of motor neurons in the LMC reliably predicts their topographic pattern of innervation of limb muscles. Motor neurons in the lateral LMC [LMC(1)] project to dorsal limb muscles, whereas motor neurons that lie in the medial $\mathrm{LMC}[\mathrm{LMC}(\mathrm{m})]$ extend to ventral limb muscles (Landmesser, 1978; Tosney and Landmesser, 1985). In contrast, motor neurons in the medial portion of the medial motor column $[\mathrm{MMC}(\mathrm{m})]$ at hindlimb levels extend their axons ventrally from the neural tube with LMC axons but take a sharp dorsal turn

\footnotetext{
Received 0ct. 19, 2003; revised Dec. 8, 2003; accepted Dec. 10, 2003.

This work was supported by United States Public Health Service Grant MH59894 to C.E.K., National Science Foundation Grant 0212326 to K.W.T., and a Muscular Dystrophy Association fellowship to S.O. J.E. was supported by National Institutes of Health training Grant 2T32GM08396-11.

Correspondence should be addressed to C. E. Krull at her present address (until April 2004), 108 Lefevre, Division of Biological Sciences, University of Missouri-Columbia, Columbia, M0 65202. E-mail: krullc@missouri.edu; permanent address: Cell and Developmental Biology, University of Michigan Medical School, Ann Arbor, Ml 48109.

J. Eberhart's and M. E. Swartz's present address: Institute of Neuroscience, University of Oregon, Eugene, OR 97403.

A. Flagg's present address: Committee of Developmental Biology, University of Chicago, Chicago, IL 60637 D0I:10.1523/JNEUROSCI.4719-03.2004

Copyright $\odot 2004$ Society for Neuroscience $\quad$ 0270-6474/04/241070-09\$15.00/0
}

and innervate epaxial muscle, derived from the somitic myotome (Tosney, 1987). Initially, MMC(m) axons are highly defasciculated in the rostral half-sclerotome, in contrast to the tightly bundled LMC axons in the spinal nerve. As development proceeds, $\mathrm{MMC}(\mathrm{m})$ axons form tight fascicles in the rostral halfsclerotome.

The mechanisms that control axon guidance and patterning of these motor neurons are beginning to be understood. EphA4 is required and sufficient for LMC(1) motor neurons to project dorsally in the hindlimb, to innervate dorsal muscles (Helmbacher et al., 2000; Eberhart et al., 2002; Kania and Jessell, 2003). Moreover, the Lim1 TF controls the expression of EphA4 in LMC(1) neurons, tying cell specification and axon guidance together molecularly (Kania and Jessell, 2003). Mice that lack the TFs Lhx3 and Lhx4 in MMC motor neurons exhibit defects in cell specification and axon pathway selection (Sharma et al., 1998, 2000). However, other studies have implicated signals in hindlimb mesoderm and the somitic dermomyotome, targets for LMC and $\mathrm{MMC}(\mathrm{m})$ axons, respectively, in axon patterning and guidance (Lance-Jones and Landmesser, 1980, 1981; Summerbell and Stirling, 1981; Whitelaw and Hollyday, 1983; Tosney, 1987; Kania et al., 2000).

Certain members of the Eph family of receptor tyrosine kinases and their ephrin ligands are expressed dynamically by motor neurons, limb mesoderm, and somites during axon pathfinding (see Fig. 1) (Ohta et al., 1996; Eberhart et al., 2000; Swartz et al., 2001b). Divided into A and B subclasses, EphA receptors interact primarily with ephrin-As, which are anchored to the 
plasma membrane by a glycosylphosphatidylinositol linkage; EphB receptors bind transmembrane ephrin-B proteins (Gale et al., 1996). Recent studies show that bidirectional signaling between Eph receptors and ephrin-Bs is required for guidance and patterning events in the developing nervous system (Kullander and Klein, 2002). Typically, interactions between Ephs and ephrins mediate inhibitory events, although recent evidence suggests that ephrins also have positive effects (Knoll et al., 2001; McLaughlin et al., 2003). The expression of these factors in multiple tissues and their capacity for bidirectional signaling has made functional analyses challenging.

We are interested in delineating the mechanisms that influence the patterning of EphA4-positive motor axons as they project to their targets. Using in ovo electroporation, we altered the activation or expression of EphA4 or its ligand, ephrin-A5, in motor neurons, or hindlimb or somitic mesoderm, leaving adjacent tissues unperturbed. Surprisingly, we found that EphA4positive motor neurons in the $\mathrm{LMC}(\mathrm{l})$ and $\mathrm{MMC}(\mathrm{m})$ respond distinctly to ephrin-A5. Furthermore, Eph phosphorylation localizes to different subcellular domains of these neuron subpopulations, suggesting distinct signaling machinery downstream of EphA4.

\section{Materials and Methods}

Embryos. Fertilized White Leghorn chicken eggs (Hy-Line International) were incubated to stages 14-28 of development (Hamburger and Hamilton, 1951), before in ovo electroporation or embryo collection and preparation for vibratome sectioning.

Immunocytochemistry. Embryos were fixed in 4\% paraformaldehyde for $2 \mathrm{hr}$ to overnight, and chicken-specific antibodies to EphA4 (Soans et al., 1994) and ephrin-A5 were applied, as previously described (Eberhart et al., 2000). Neurofilament antibody (RMO 270.3) was used to label all axons (Lee et al., 1987). Islet 1/2 (39.4D5) and Lhx3 antibodies were obtained from the Developmental Studies Hybridoma Bank (Iowa City, IA), under the auspices of the National Institute of Child Health and Human Development, and maintained by the University of Iowa, Department of Biological Sciences (Iowa City, IA). Anti-phosphorylated Eph antibody $(0.4 \mu \mathrm{g} / \mathrm{ml}$; Shamah et al., 2001), kindly provided by Mike Greenberg (Harvard, Boston, MA), was applied to embryo sections. All antibodies were applied as previously described (Eberhart et al., 2000).

In ovo electroporation. All EphA4 and ephrin-A5 DNA inserts were cloned into the pMES vector, which contains a chick $\beta$ actin promoter/ cytomegalovirus IE enhancer with an internal ribosomal entry siteenhanced green fluorescent protein (EGFP) (Swartz et al., 2001a,b; Eberhart et al., 2002). Plasmid DNA encoding kinase-inactive EphA4/EGFP $(4 \mu \mathrm{g} / \mu \mathrm{l})$, full-length EphA4/EGFP $(3 \mu \mathrm{g} / \mu \mathrm{l})$, or full-length ephrin-A5/ EGFP $(3 \mu \mathrm{g} / \mu \mathrm{l})$ was electroporated at hindlimb levels into the ventral neural tube at stages $15-17$, the somitic sclerotome at stage 16 , or lateral plate mesoderm that generates the hindlimb at stages $16 / 17$, according to established procedures (Swartz et al., 2001a,b; Eberhart et al., 2002; Krull, 2004). For electroporation of lateral plate mesoderm, DNA was injected into the coelom, which underlies the splanchnic mesoderm that will form the limb at lumbosacral (hindlimb) levels, as previously described (Swartz et al., 2001b). Control embryos were transfected with pCAX (3 $\mu \mathrm{g} / \mu \mathrm{l})$, which contains the same promoter/enhancer as pMES, to express EGFP alone (Osumi and Inoue, 2001; Swartz et al., 2001a). After electroporation, embryos were reincubated to stages 23-28 of development. Successful neural tube transfection was verified in ovo using an Olympus (Tokyo, Japan) fluorescence dissecting microscope equipped with EGFP optics. Embryos were then collected and prepared for retrograde labeling (see below) or fixed for $2 \mathrm{hr}$ to overnight in $4 \%$ paraformaldehyde, and prepared for vibratome sectioning where transverse or sagittal sections were acquired.

Retrograde labeling. Embryos electroporated with the full-length EphA4/EGFP or kinase-inactive EphA4/EGFP construct in the ventral neural tube or full-length ephrin-A5/EGFP construct in the hindlimb mesoderm were grown to stages $26-28$ and collected in Ringer's solution.

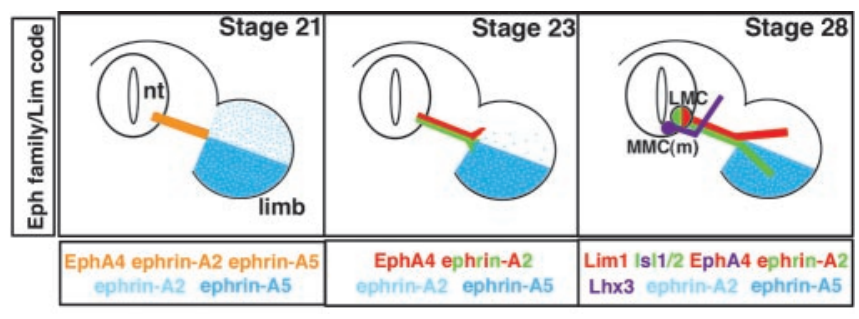

Figure 1. The expression of Eph family members and the Lim code during the development of motor axon projections to target muscle. All diagrams illustrate expression patterns at the level of the crural plexus in the hindlimb. Left, All motor axons express EphA4, ephrin-A2, and ephrin- $\mathrm{A5}$ (gold) when they reach the base of the hindlimb at stage 21. Ephrin- $\mathrm{A} 2$ is diffusely expressed across the hindlimb mesoderm, whereas ephrin- $\mathrm{A} 5$ is restricted to the ventral hindlimb. Middle, As motor axons initiate sorting in the plexus at stage 23, EphA4 is segregated to the forming dorsal nerve trunk (red) and presumably downregulated on the forming ventral nerve trunk. Ephrin- $\mathrm{A} 5$ protein is absent on motor axons whereas ephrin- $\mathrm{A} 2$ remains on all motor axons (red, green). Right, When the adult pattern of axon projections have formed, motor neurons in the LMC(I) (green) express Lim1, EphA4, and ephrin-A2 and enter the dorsal hindlimb, which lacks ephrins. Motor neurons in the $\operatorname{LMC}(\mathrm{m})$ (red) project to the ventral hindlimb, which is rich in ephrins (blue) and express $\mid \mathrm{s} 11 / 2$ and ephrin-A2, but not EphA4. MMC(m) neurons (purple) project to epaxial muscle and express Lhx3, Isl1/2, and EphA4 (this study).

Retrograde labeling of $\mathrm{MMC}(\mathrm{m})$ cell bodies via the dorsal ramus or the LMC cell bodies via the dorsal and ventral nerve trunks was performed, as previously described (see Fig. 5) (Sharma et al., 1998; Eberhart et al., 2002). To quantify the number of $M M C(m)$ axons that had misprojected into the DRG, MMC $(\mathrm{m})$ neuron cell bodies that were EphA4/EGFP- and Lhx3-positive and dextran-backfilled from the DRG were counted, in comparison with all EphA4/EGFP-positive MMC(m) neurons. Twentyseven percent (59 neurons) of a total of $220 \mathrm{MMC}(\mathrm{m})$ neurons that ectopically expressed EphA4/EGFP misprojected into the DRG. In controls, where EGFP was expressed in $\mathrm{MMC}(\mathrm{m})$ neurons, no axon misprojections occurred ( $n=235$ neurons/10 embryos).

Confocal microscopy. Optical sections at $2 \mu \mathrm{m}$ intervals were collected from vibratome sections labeled with EGFP and antibodies using a BioRad (Hercules, CA) Radiance 2000 laser-scanning confocal microscope (Molecular Cytology Core, University of Missouri-Columbia), as previously described (Eberhart et al., 2002). Z series stacks of 10-30 $\mu$ m were assembled from sectioned material using Metamorph software. Images were processed and compiled into figures using Adobe Photoshop 7.0.

Cell culture. For cell culture experiments, embryos at stage 26-28 were backfilled at hindlimb levels from the dorsal ramus to label $\mathrm{MMC}(\mathrm{m})$ neurons, from the femoral nerve to label LMC(l) neurons, and the ventral nerve trunk to label $\mathrm{LMC}(\mathrm{m})$ neurons at the crural plexus using either Alexa 488 or Alexa 568 10,000 molecular weight dextrans, as previously described (see Fig. 5) (Sharma et al., 1998; Eberhart et al., 2002). This approach results in the unequivocal labeling of distinct $\mathrm{MMC}(\mathrm{m})$, $\mathrm{LMC}(1)$, and $\mathrm{LMC}(\mathrm{m})$ neurons (Ensini et al., 1998). After retrograde labeling, embryos were visually inspected to directly verify cell body locations, coincident with dextran labeling, in the mediolateral and anteroposterior axes before neural tube dissection. Neural tubes from backfilled embryos were isolated, trypsinized for $10 \mathrm{~min}$, and mechanically dissociated into single cells. These single cells were then plated at low density to avoid cell-cell contact on nitrocellulose-coated $35 \mathrm{~mm}$ tissue culture dishes containing substrate-bound, clustered ephrin-A5-Fc $(5 \mu \mathrm{g} / \mathrm{ml})$ and laminin $(100 \mu \mathrm{g} / \mathrm{ml})$. Control cells that were backfilled previously were plated on Fc $(5 \mu \mathrm{g} / \mathrm{ml})$ and laminin. Neurite lengths on all substrates were then measured for $\mathrm{MMC}(\mathrm{m})$ neurons, $\mathrm{LMC}(\mathrm{l})$ neurons, $\mathrm{LMC}(\mathrm{m})$ neurons, and control neurons using Openlab software (Improvision, Lexington, MA).

\section{Results}

Motor neurons in the ventral neural tube that project to target muscles express a unique combination of Lim transcription factors that are thought to specify motor neuron identity (Fig. 1) (Tsuchida et al., 1994). For example, motor neurons in the 
LMC(1) express Lim 1 and Islet 2 and innervate dorsal muscles in the hindlimb, whereas $\mathrm{LMC}(\mathrm{m})$ motor neurons express Islet $1 / 2$ and innervate ventral hindlimb muscles. In contrast, $\mathrm{MMC}(\mathrm{m})$ neurons express Lhx3 and Islet1/2 and extend to epaxial muscle, derived from the somitic myotome. In addition, these motor neurons and their axon projections express certain members of the Eph family in a dynamic manner (Fig. 1) (Kilpatrick et al., 1996; Ohta et al., 1996; Eberhart et al., 2000). EphA4 becomes localized gradually to LMC(1) neurons and their axon projections at the level of the crural plexus, whereas all LMC neurons and their axons express ephrin-A2. In addition, the hindlimb mesoderm exhibits a complicated pattern of ephrin expression during the stages when motor axons project to their limb targets. When motor axons stall at the base of the limb, ephrin-A2 protein is diffusely localized across the hindlimb mesoderm. As motor axons sort in the plexus to form dorsal and ventral nerve trunks, ephrin-A2 and -A5 proteins are restricted to the ventral portion of the hindlimb mesoderm. Thus, EphA4-positive, dorsal axons enter dorsal limb territory that is devoid of ephrins, and EphA4-negative, ventral axons enter ventral limb territory rich in ephrins. Recent studies have shown that EphA4 is sufficient to guide $\mathrm{LMC}(\mathrm{m})$ axons along a dorsal trajectory in the hindlimb (Eberhart et al., 2002; Kania and Jessell, 2003). However, it is not understood whether EphA4-positive axons use ephrins in hindlimb mesoderm to select their axon pathways.

\section{LMC(1) axons avoid entering ephrin-A5} domains in limb mesoderm

To determine whether EphA4-positive LMC(1) axons use ephrin-A5 expressed in ventral hindlimb mesoderm to extend accurately into the limb, we ectopically expressed ephrin-A5 broadly in hindlimb mesoderm and examined subsequent effects on motor axon projections at stages 24-28 (Swartz et al., 2001b). In controls, where EGFP was expressed in hindlimb mesoderm at the base of the limb, dorsal and ventral nerve trunks formed correctly (Fig. $2 A, B)$ ( $n=8$ of 8 embryos). In experimental embryos, EphA4-positive, dorsal motor axons stopped at the base of the hindlimb when confronted with a swath of ectopic ephrin-A5, avoiding entry, whereas an EphA4-negative nerve trunk entered the hindlimb on its normal timetable (Fig. 2C,D) ( $n=14$ of 14 embryos). At later stages, as limb morphogenesis progressed, EphA4-positive axons entered the limb by apparently navigating around regions of ectopic ephrin-A5 expression (data not shown). To determine whether dorsoventral axon sorting was disrupted in embryos where EphA4 axons stalled at the base of the hindlimb when ephrin-A5 was ectopically expressed, dextrunk have sorted properly.
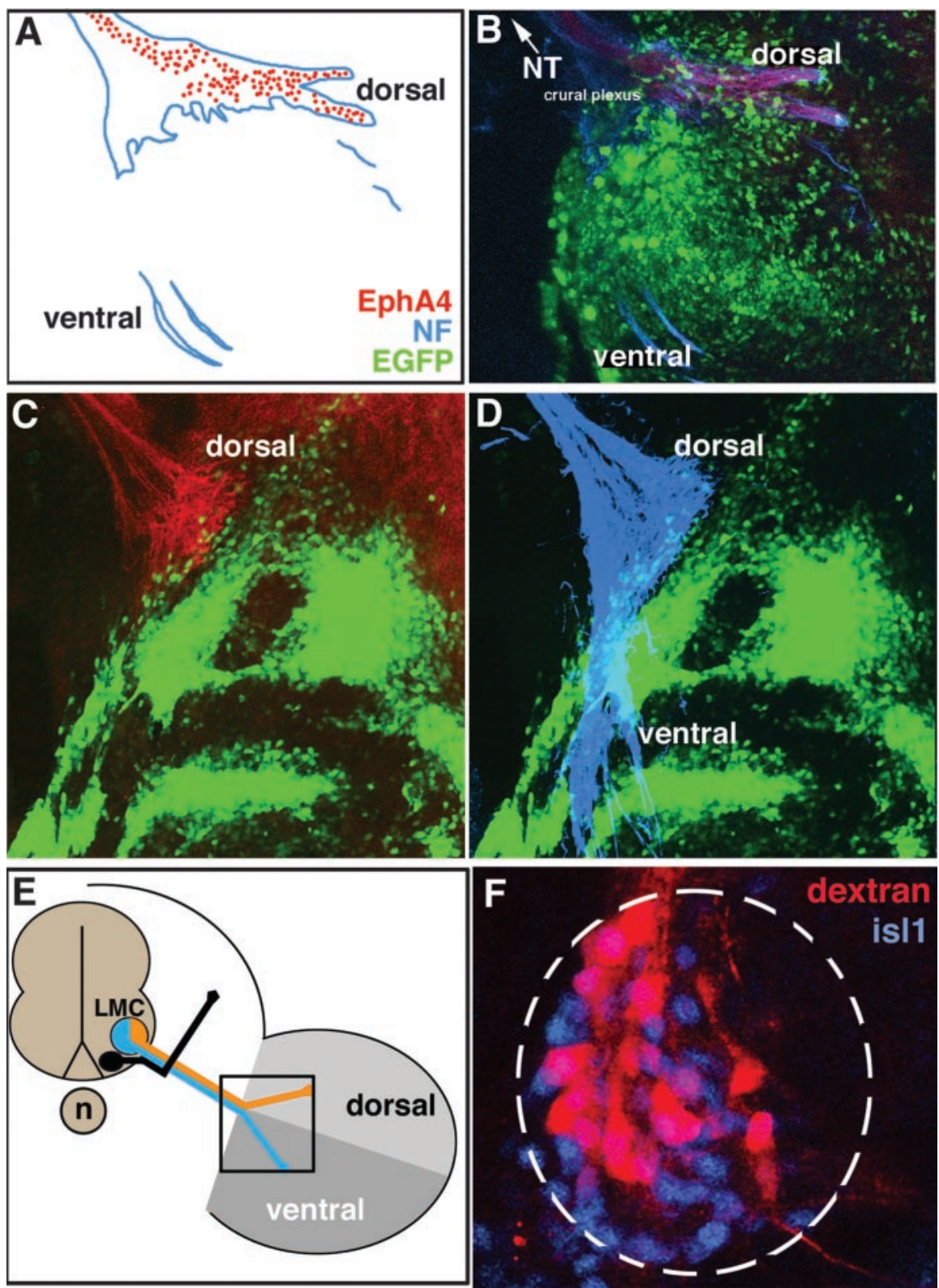

Figure 2. EphA4+ LMC(I) axons are prohibited from limb entry by ectopic expression of ephrin- $\mathrm{A} 5 \mathrm{in}$ limb mesoderm. $A, B$, Schematic diagram and image showing that EphA4+ dorsal axons (red) and neurofilament antibody-labeled axons (blue) of the crural plexus enter the limb normally when EGFP (green) is expressed in limb mesoderm, controls. C, When ephrin-A5/EGFP is ectopically expressed in limb mesoderm, dorsal EphA4+ axons do not enter the limb. D, Neurofilament (NF) antibody reveals that axons in the ventral nerve trunk enter normally in the presence of ectopic ephrin-A5/EGFP. E, Schematic diagram showing the views of $L M C$ axons depicted in $A-D$, in boxed area. $F$, Backfills of the ventral nerve trunk in embryos where ephrin- $A 5$ was ectopically expressed in limb mesoderm reveals that $L M C(m)$ cell bodies are labeled, indicating that axons in the ventral nerve

tran amines were injected into the ventral nerve trunk to label motor neuron cell bodies retrogradely. Motor neurons that projected axons ventrally into the hindlimb had cell bodies positioned correctly in the $\mathrm{LMC}(\mathrm{m})$, showing that axon sorting into the ventral nerve trunk was normal (Fig. $2 F)$ ( $n=6$ of 6 embryos). These results indicate that EphA4-positive LMC(1) motor axons are strongly inhibited from entry into the hindlimb by ephrin-A5.

\section{Expression of EphA4 and ephrin-A5 by MMC(m) axons} and sclerotome

As we examined EphA4 expression by LMC(1) neurons, we found that $\mathrm{MMC}(\mathrm{m})$ axons at hindlimb levels also expressed EphA4. 

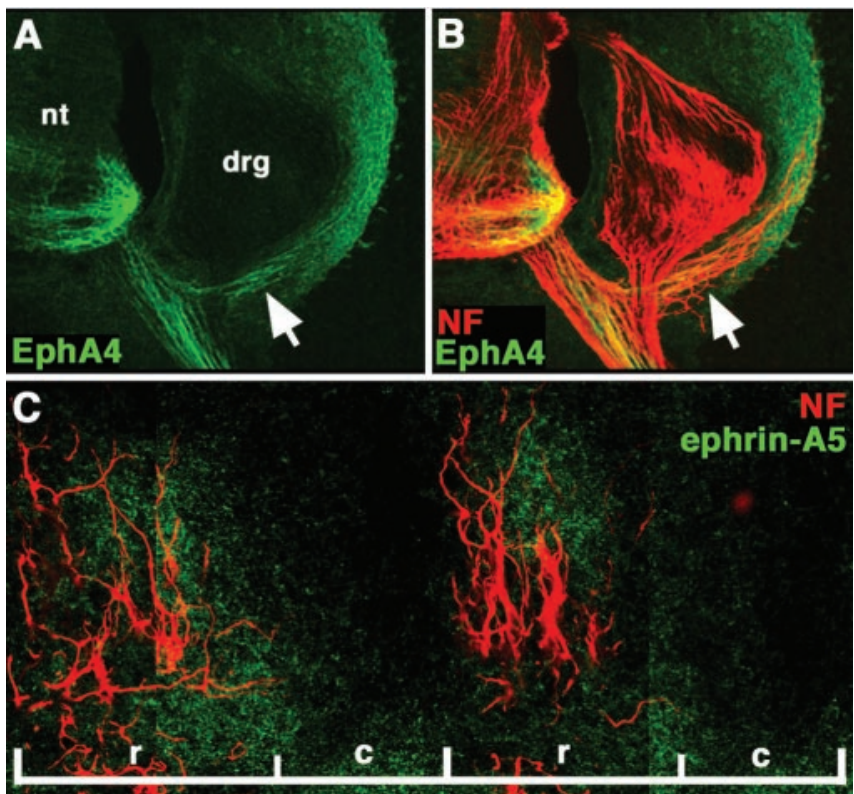

Figure 3. EphA4 localizes predominantly to $M M C(m)$ axon shafts; ephrin- $A 5$ is expressed in rostral half-sclerotome. A, B, Transverse section showing that EphA4 protein (green) strongly marks $\mathrm{MMC}(\mathrm{m})$ axon shafts (arrow) that lie lateral to the dorsal root ganglia (drg), at stage 26. Neurofilament (NF) antibody staining labels all axons (red). C, Sagittal section showing that ephrin-A5 protein (green) localizes primarily to the rostral half-sclerotome, occupied by $\operatorname{MMC}(\mathrm{m})$ axons that are labeled by NF antibody (red). nt, Neural tube; r, rostral half-sclerotome; c, caudal half-sclerotome.

Previous studies have shown that EphA4 is limited to motor neurons at limb levels (Fukushima et al., 1996; Eberhart et al., 2000), whereas EphA3 localizes to MMC neurons at non-limb levels (Kilpatrick et al., 1996). Expression on MMC(m) axons initiated at stage 25 , when these axons have begun to accumulate lateral to the dorsal root ganglia (DRG) to innervate axial muscle (data not shown). EphA4 was highly expressed on $\mathrm{MMC}(\mathrm{m})$ axon shafts at stage 26 (Fig. $3 A, B$ ) and persisted beyond stage 28 , whereas expression of EphA4 was weak on the distal tips of $\mathrm{MMC}(\mathrm{m})$ axons. To determine the ligand distribution for EphA4, we analyzed the expression of ephrin-A2, ephrin-A5, and ephrin-A6 proteins. Ephrin-A5 localized primarily to the rostral half-sclerotome of the somite, where $\mathrm{MMC}(\mathrm{m})$ axons travel as they extend to target axial muscles (Fig. 3C). In contrast, neither ephrin-A2 nor ephrin-A6 localized to $\mathrm{MMC}(\mathrm{m})$ neurons or their axon pathways (data not shown). Collectively, these data indicate that $\mathrm{MMC}(\mathrm{m})$ axons normally enter ephrin-A5-positive territories, in contrast to $\mathrm{LMC}(\mathrm{l})$ axons which do not enter ephrin-A5 domains in the limb mesoderm.

\section{Blocking EphA4 signaling in $\mathrm{MMC}(\mathrm{m})$ neurons: axons enter the caudal half-sclerotome}

To determine the contribution of EphA4 signaling to the patterning of $\mathrm{MMC}(\mathrm{m})$ axon projections in the rostral half-sclerotome, kinase-inactive EphA4 (kiEphA4)/EGFP was expressed in $\mathrm{MMC}(\mathrm{m})$ neurons at stages 15-17 to disrupt EphA4 signaling, using in ovo electroporation (Eberhart et al., 2002). KiEphA4 acts as a dominant negative, to abolish phosphorylation that drives activation of the WT EphA4 receptor in the presence of ephrin stimulation (Ethell et al., 2001). In control embryos transfected with plasmid DNA encoding EGFP alone, MMC(m) axons were confined to the rostral half-sclerotome (Fig. $4 A)(n=14$ of 14 embryos). In experimental embryos in which EphA4 signaling
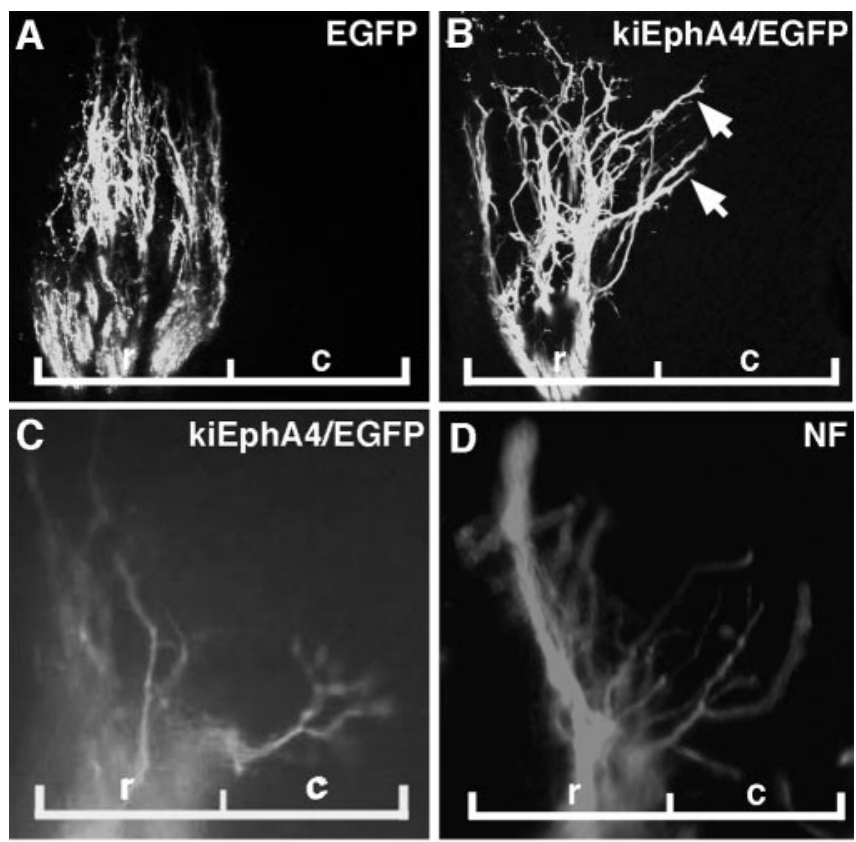

Figure 4. $M M C(m)$ axons grow aberrantly into the caudal half-sclerotome when EphA4 signaling is blocked. All images are sagittal sections through $\mathrm{MMC}(\mathrm{m})$ axons, at the level of a single somite. A, At stage 26, MMC(m) axons grow normally in the rostral half-sclerotome when EGFP is expressed in MMC $(\mathrm{m})$ neurons, controls. $B$, At stage 26 , some $M M C(\mathrm{~m})$ axons extend abnormally (arrows) into the caudal half-sclerotome when kinase-inactive EphA4/EGFP is expressed in $\mathrm{MMC}(\mathrm{m})$ neurons to block EphA4 phosphorylation. C, D, At stage 28, MMC(m) axons are localized inappropriately in the caudal half-sclerotome when EphA4 signaling is blocked. Green, EGFP signal; red, NF antibody labeling. r, rostral half-sclerotome, c, caudal half-sclerotome.

was blocked by expression of kiEphA4, MMC(m) axons grew aberrantly into the caudal half-sclerotome (Fig. $4 B-D)(n=10$ of 10 embryos). $\mathrm{MMC}(\mathrm{m})$ axons did not project aberrantly into the hindlimb, when EphA4 signaling was blocked (data not shown). These results indicate that EphA4 activation is required in $\mathrm{MMC}(\mathrm{m})$ neurons to maintain their axon projections in the rostral half-sclerotome.

\section{Prematurely expressing EphA4 in MMC(m) neurons: axons} enter novel ephrin-A5-positive domains

To analyze further the function of EphA4, full-length EphA4/ EGFP was expressed ectopically in $\mathrm{MMC}(\mathrm{m})$ neurons before the development of their axon projections (i.e., stages 15-17), using in ovo electroporation (Eberhart et al., 2002). Each transfected embryo had at least one axon that inappropriately projected into novel dorsal territories, including the neural tube (Fig. 5A) and the forming DRG (Fig. 5C,D). Interestingly, ephrin-A5 was strongly expressed at the stage when $\mathrm{MMC}(\mathrm{m})$ axons misprojected into these new territories (Fig. 5B). At times, the cell body of a misprojecting axon could be identified visually as a MMC(m) neuron (Fig. 5A). Furthermore, dextrans were applied to retrogradely label neuronal cell bodies that had misprojected into the DRG; cell bodies located in the $\mathrm{MMC}(\mathrm{m})$ were retrogradely labeled (Fig. 5E,F). We quantified the number of $\mathrm{MMC}(\mathrm{m})$ axons that projected aberrantly into the DRG, using a combination of retrograde labeling with dextrans, Lhx3 antibody labeling, and EGFP signal. Approximately 27\% of the total MMC(m) neurons ( $n=220$ neurons/10 embryos) that expressed EphA4/EGFP projected aberrantly into the DRG. MMC(m) axons that prematurely expressed EphA4 never projected incor- 

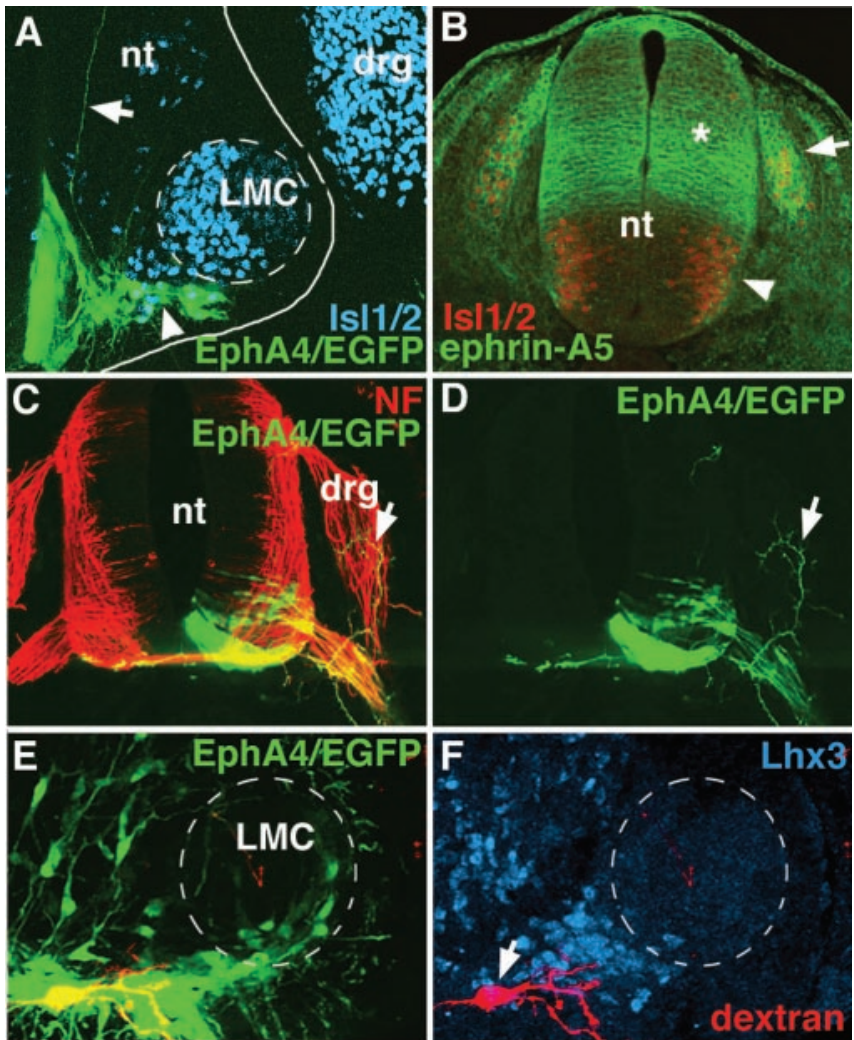

Figure 5. $M M C(m)$ axons extend inappropriately into novel, ephrin-A5-positive territories when EphA4/EGFP is prematurely expressed. A, Transverse section through the neural tube (nt) $2 \mathrm{~d}$ after electroporation of EphA4/EGFP construct (green) into MMC(m) neurons shows that a single Is 11/2-positive axon (arrow) misprojects into the dorsal neural tube. B, Transverse section, labeled with ephrin-A5 (green) and isl1/2 (red) antibodies, shows that ephrin- $A 5$ is strongly expressed in the dorsal half $\left({ }^{*}\right)$ neural tube $(n t)$, lateral to recently postmitotic neurons in the ventral neural tube (arrowhead), and in the forming DRG (arrow) at the stage when $\operatorname{MMC}(\mathrm{m})$ axons misproject into the neural tube $(A)$ or DRG $(C, D)$. C, D, Transverse section showing that an EphA4/EGFP-positive axon (arrow) is found in the dorsal root ganglia (drg). Red, NF antibody staining; green, EGFP signal. E, F, High magnification of transverse section through ventral neural tube showing that a $\mathrm{MMC}(\mathrm{m})$ neuron cell body (arrow) has been backfilled from an aberrant axon in the DRG. Note that the LMC is devoid of dextran-labeled neurons. Green, EGFP signal; red, dextran amines; blue, Lhx3 antibody staining to label MMC(m) neurons.

rectly into the hindlimb mesoderm, as shown by retrograde labeling from the dorsal and ventral nerve trunks of the crural plexus (data not shown; Eberhart et al., 2002). In control embryos expressing EGFP, MMC(m) neurons never projected erroneously into the neural tube, DRG, or hindlimb (data not shown; $n=10$ embryos). Moreover, LMC(m) neurons that ectopically expressed EphA4 did not misproject into the neural tube or DRG (Eberhart et al., 2002). These data suggest that ectopic expression of EphA4 in MMC $(\mathrm{m})$ neurons is sufficient to drive a portion of their axons dorsally, into novel ephrin-A5-rich embryonic territories and further supports the idea that ephrin-A5 acts positively on $\mathrm{MMC}(\mathrm{m})$ neurons.

$\mathrm{MMC}(\mathrm{m})$ axons enter the caudal half-sclerotome, where ephrin-A5 is ectopically expressed

To analyze the influence of ephrin-A5 on $\mathrm{MMC}(\mathrm{m})$ axon projections, we expanded the domain of ephrin-A5 expression in the somitic sclerotome, using in ovo electroporation (Swartz et al., 2001a). Some MMC(m) axons grew inappropriately into ectopic regions of ephrin-A5/EGFP expression in the caudal halfsclerotome (Fig. 6) ( $n=8$ of 10 embryos). These axons expressed
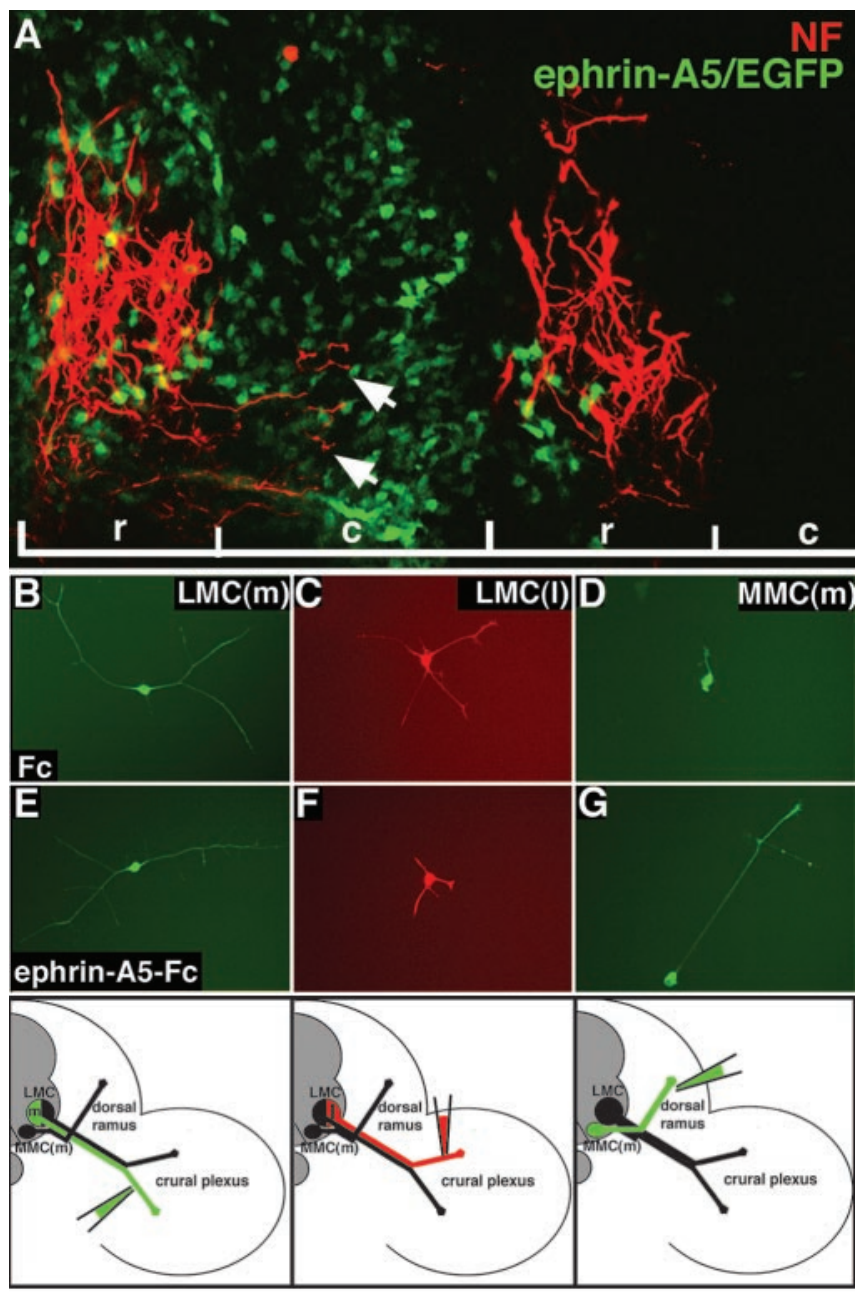

Figure 6. Neuron responses to ephrin-A5 are distinct. A, Sagittal section showing that NF+ $M M C(m)$ axons (red) grow aberrantly (arrows) into the caudal half-sclerotome when the domain of ephrin-A5 expression (green) in the sclerotome is expanded. r, Rostral half-sclerotome; $c$, caudal half-sclerotome. $B, E, L M C(m)$ neurons that are EphA4- demonstrate robust growth on ephrin- $A 5$ or in controls $(F C)$. C, $F$, The growth of $L M C(I)$ neurons that express EphA4 is reduced on ephrin-A5 substrates, compared with controls $(C) . D, G, M M C(m)$ neurons display poor growth in control cultures but exuberant neurite growth on ephrin-A5 substrates. Bottom, Schematic diagrams showing that retrograde labeling of the ventral nerve trunk to label $\operatorname{LMC}(\mathrm{m})$ neurons, of the dorsal nerve trunk to mark LMC(I) neurons, and of the dorsal ramus to label $M M C(m)$ neurons is precise.

EphA4, as verified by antibody staining (data not shown). In controls, EGFP-positive MMC(m) axons localized to the rostral portion of the sclerotome (data not shown; $n=5$ of 5 embryos). Collectively, these data indicate that EphA4-ephrin-A5 signaling in vivo acts in a positive manner to constrain $\mathrm{MMC}(\mathrm{m})$ axons to the rostral sclerotome.

\section{Neurite growth in vitro mimics in vivo motor neuron responses to ephrins}

To further examine the responsiveness of distinct subsets of motor neurons to ephrin-A5 substrates, axons of LMC(m), LMC(l), and $\mathrm{MMC}(\mathrm{m})$ neurons were backfilled with dextran amines at stages $27-28$ of development, to label distinct motor neuron cell bodies (Fig. 6, bottom). Labeled neurons were cultured in isolation on separate tissue culture plates coated with clustered ephrin-A5-Fc/laminin. Control dishes contained isolated neurons grown on Fc/laminin. These neuron subpopulations exhibited levels of neurite outgrowth on ephrin-A5 substrates in vitro that 
correlated with their in vivo responsiveness: LMC(1) neurons that expressed EphA4 exhibited weak neurite growth on ephrin-A5 ( $x=46 \mu \mathrm{m} ; n=17$ cells) (Fig. $6 F)$, comparable to control LMC(1) neurons grown on Fc ( $x=54 \mu \mathrm{m} ; n=10$ cells) (Fig. $6 C)$. In contrast, $\mathrm{MMC}(\mathrm{m})$ neurons that expressed EphA4 displayed extensive neurite outgrowth on ephrin-A5 ( $x=218 \mu \mathrm{m} ; n=38$ cells) (Fig. 6G), compared with control MMC $(\mathrm{m})$ neurons grown on $\mathrm{Fc}(x=58 \mu \mathrm{m} ; n=15$ cells) (Fig. $6 D)$. $\mathrm{LMC}(\mathrm{m})$ neurons that do not express EphA4 displayed moderate levels of neurite growth when grown on ephrin-A5 $(x=126 \mu \mathrm{m} ; n=14$ cells $)$ (Fig. $6 E$ ), comparable to control LMC $(\mathrm{m})$ neurons grown on $\mathrm{Fc}$ $(x=122 \mu \mathrm{m} ; n=12$ cells) (Fig. $6 \mathrm{~B})$. No significant differences in neurite numbers were present under any treatment condition. These data demonstrate that regenerating neurons in vitro exhibit similar responses to ephrin-A5 as described in vivo, supporting the notion that distinct subsets of motor neurons that express EphA4 respond differentially to ephrin-A5.

Eph activation localizes to discrete subcellular domains of $\mathrm{LMC}(\mathrm{l})$ and $\mathrm{MMC}(\mathrm{m})$ neurons

To examine whether the subcellular localization of Eph activation could contribute to the differential responses of these axon populations, we examined the phosphorylation status or activation of Eph receptors on $\mathrm{LMC}$ and $\mathrm{MMC}(\mathrm{m})$ axons in vivo, using an anti-phosphorylated Eph antibody (Shamah et al., 2001). LMC axon shafts at the level of the spinal nerve (Fig. 7A, $B)(n=$ 2 embryos), crural plexus (Fig. 6C,D) ( $n=2$ embryos), and the distal tips of the dorsal nerve trunk occupied by LMC(l) axons (Fig. $7 E-H)$ ( $n=6$ embryos) exhibited Eph phosphorylation. In contrast, $\mathrm{MMC}(\mathrm{m})$ axons displayed Eph activation localized to their axon shafts (Fig. 8 ) ( $n=6$ embryos) but phosphorylation at their distal tips was very weak (Fig. 8) ( $n=6$ embryos). This pattern is consistent with that of EphA4 expression (Eberhart et al., 2000). These data argue that the EphA4 signaling machinery localizes to distinct domains of the axons of $\mathrm{MMC}(\mathrm{m})$ and LMC(1) neurons.

\section{Discussion}

From our findings, we conclude that EphA4-ephrin-A5 signaling can exert positive and negative effects on the patterning of axon projections from chick $\mathrm{MMC}(\mathrm{m})$ and $\mathrm{LMC}(\mathrm{l})$ motor neurons. Several lines of evidence support this conclusion. First, ectopic expression of ephrin-A5 in the dorsal limb mesoderm prevents EphA4-positive LMC(1) axons from entry on their typical timetable. Normally, EphA4-positive axons project into the dorsal limb, where ephrin-A5 is absent (Eberhart et al., 2000). Second, blocking EphA4 signaling in $\mathrm{MMC}(\mathrm{m})$ neurons or ectopically expressing ephrin-A5 in the caudal half-sclerotome allows $\mathrm{MMC}(\mathrm{m})$ axons to extend inappropriately into the caudal halfsclerotome. Third, premature ectopic expression of EphA4 in $\mathrm{MMC}(\mathrm{m})$ neurons before their axons extend through the rostral half-sclerotome drives a portion of their projections into novel, ephrin-A5-positive regions. Fourth, isolated LMC(1) and $\mathrm{MMC}(\mathrm{m})$ neurons in vitro exhibit similar responses to ephrin-A5 coated substrates as those shown in vivo. LMC(1) neurons exhibit low levels of neurite growth, whereas $\mathrm{MMC}(\mathrm{m})$ neurons display robust neurite growth.

One mechanism that could contribute to altered axon projections is that motor neuron identity or settling patterns in the neural tube are changed when EphA4 signaling is blocked or EphA4 is prematurely expressed in $\mathrm{MMC}(\mathrm{m})$ neurons. However, we have not observed such alterations: $\mathrm{MMC}(\mathrm{m})$ neurons are positioned medial to the LMC at hindlimb levels and exhibit
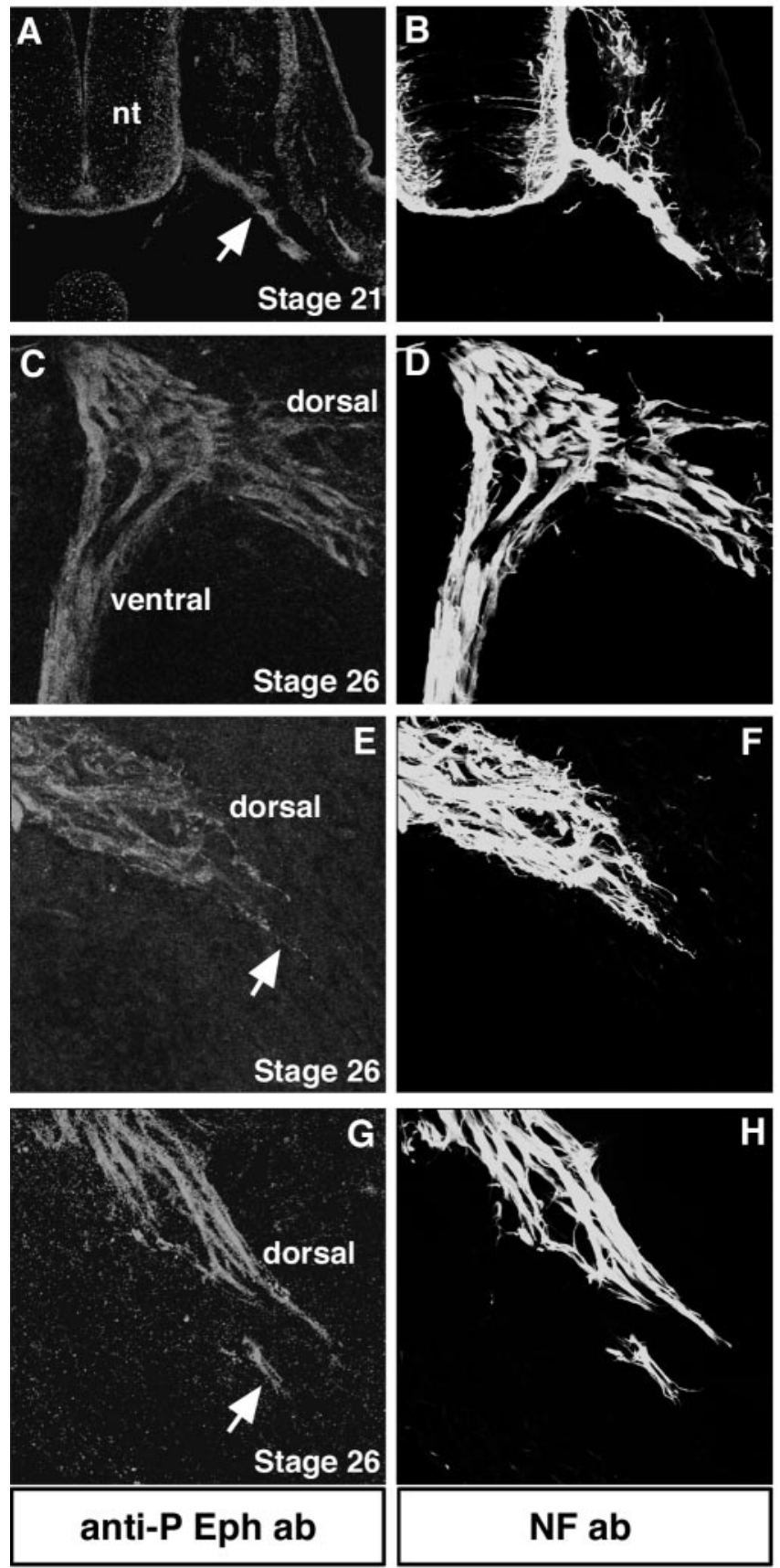

Figure 7. Eph phosphorylation localizes to the axon shafts and distal tips of LMC neurons in vivo. All transverse sections were labeled with anti-phosphorylated Eph antibody to detect Eph activation (red) and NF antibody to label all axons (green). $A, B$, At stage 21, before motor axons arrive to the base of the limb, they exhibit Eph phosphorylation (arrow). nt, Neural tube. C, D, At the level of the crural plexus at stage 26, dorsal and ventral projecting axons display Eph phosphorylation. E-H, Distal tips of LMC(I) axons (arrows) show Eph phosphorylation.

Islet1/2 and Lhx 3 immunoreactivity, as is typical. Furthermore, recent studies have shown that Lim1 and Islet1 transcription factors control motor neuron settling patterns, independent of Eph family members (Kania and Jessell, 2003).

What accounts mechanistically for these different responses of EphA4-positive motor neurons to ephrin-A5? Three possible explanations emerge, which are not mutually exclusive: (1) the normal inhibition of the caudal sclerotome for $\mathrm{MMC}(\mathrm{m})$ axons has been altered in our manipulations, perhaps changing the rostrocaudal polarity of the somites or masking the repulsion inher- 
ent to this region of the somites, (2) distinct signaling molecules downstream of EphA4 are active in different subsets of motor neurons, or (3) EphA4 activation localizes to distinct regions of $\mathrm{MMC}(\mathrm{m})$ versus LMC(l) neurons.

To address the possibility that the rostrocaudal polarity of the sclerotome may have been altered by ectopically expressing ephrin-A5, allowing $\mathrm{MMC}(\mathrm{m})$ axons to now enter this normally inhibitory territory, we examined the expression of distinct markers localized to the rostral and caudal somitic domains, including caudally expressed ephrin-B1. In all cases, the rostrocaudal polarity of the somites was unaltered, indicating that this mechanism could not account for the inappropriate entry of $\mathrm{MMC}(\mathrm{m})$ axons into the caudal half-sclerotome (data not shown). Furthermore, EphA4 protein, a potentially positive signal for $\mathrm{MMC}(\mathrm{m})$ axons, was not upregulated in the caudal half-sclerotome upon expansion of the ephrin-A5 expression domain (data not shown).

Interestingly, $\mathrm{MMC}(\mathrm{m})$ axons did not grow exuberantly beyond the borders of an individual somite when EphA4 signaling was blocked in $\mathrm{MMC}(\mathrm{m})$ neurons or when the domain of ephrin-A5 expression in the somite was expanded. This is most likely caused by the presence of an intersomitic blood vessel between each somite that acts as a physical barrier to axon advance (K. Tosney, unpublished observations).

We cannot exclude the possibility that ectopic ephrin-A5 in the somites abrogates the normal inhibition of the caudal halfsclerotome for $\mathrm{MMC}(\mathrm{m})$ axons, acting as a positive cue to make that environment more seductive for growing axons. However, ephrin-A5 does not serve to mask any inhibitory effect of Eph family members localized to the caudal half-sclerotome on $\operatorname{MMC}(\mathrm{m})$ axons. Neither ephrin-B1 nor EphA7 in the caudalhalf sclerotome are required to prohibit EphA4-positive $\mathrm{MMC}(\mathrm{m})$ axons from entering this domain (Koblar et al., 2000) (C. E. Krull, unpublished data).

EphA4-positive MMC(m) and LMC(l) neurons may possess distinct signaling components downstream of EphA4 that account for their different responsiveness to ephrin-A5. The strongest candidate to date is ephexin, which binds specifically to EphA4 and activates Rho, Rac, or Cdc42, dependent on cellular context (Shamah et al., 2001). Other EphA4 signaling components have not been identified thus far. Experiments are in progress to determine whether ephexin contributes to the different responses of $\mathrm{LMC}(\mathrm{l})$ and $\mathrm{MMC}(\mathrm{m})$ neurons to ephrin-A5.

Our results and others demonstrate that EphA4 forward signaling is required for both $\mathrm{MMC}(\mathrm{m})$ and $\mathrm{LMC}(\mathrm{l})$ axon projections and patterning (Helmbacher et al., 2000; this study) (S. O'Connell and C. E. Krull, unpublished data). However, we strongly suspect that the molecular machinery that underlies EphA4 signaling is different, based on where EphA4 is activated or phosphorylated on $\mathrm{MMC}(\mathrm{m})$ and $\mathrm{LMC}(\mathrm{l})$ axons. We found that Eph phosphorylation localizes to LMC axon shafts and the distal tips of their axons, where growth cones are thought to sample the local environment and make pathway selection decisions. Eph phosphorylation on LMC(1) axons represents the ac-
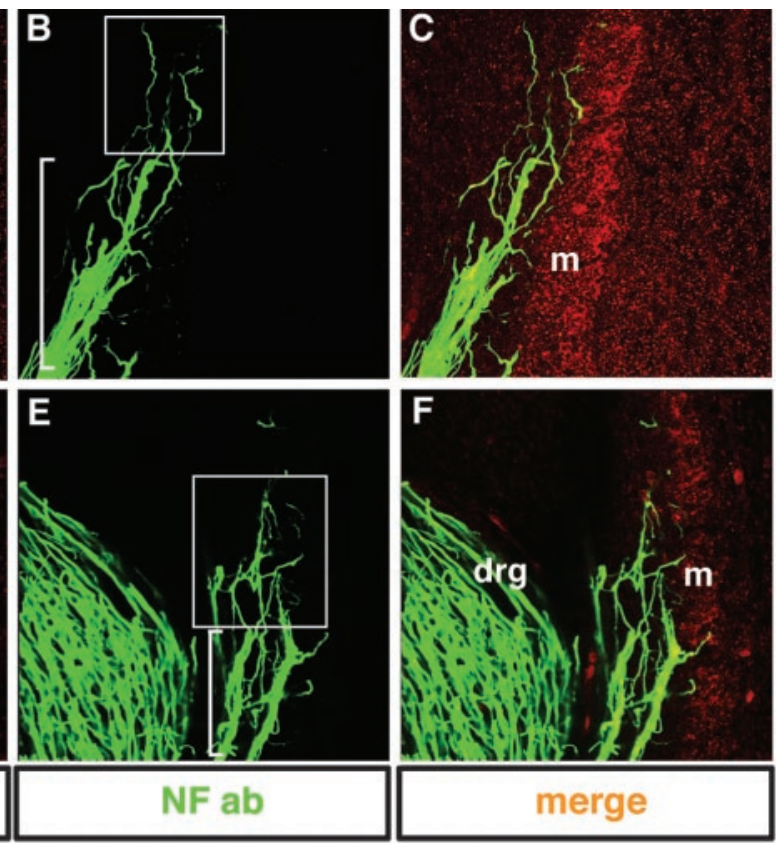

C(m) neurons show Eph phosphorylation at their axon shafts but negligible signal at their distal axon tips in vivo. (boxed area). $D-F$, In another embryo, $M M C(m)$ axon shafts show strong activation of Eph (bracket in $A$ ) but very

tivation of EphA4, whereas Eph phosphorylation on LMC(m) axons is contributed presumably by EphB2 (Eberhart et al., 2000) (R. McLennan and C. E. Krull, unpublished observations). In contrast, Eph phosphorylation is predominant on $\mathrm{MMC}(\mathrm{m})$ axon shafts and negligible on their distal tips. The distinct localizations of activated EphA4 on growth cones and axon shafts could indeed account for the differential responses of LMC(1) and $\mathrm{MMC}(\mathrm{m})$ neurons to ephrin-A5 in vivo. Previous studies have shown that the upregulation of guidance factors on distal segments of axons can influence guidance and axon responses (Keleman et al., 2002). Axons and growth cones are indeed capable of protein translation and export to their cell surfaces (Brittis et al., 2002) and protein synthesis and degradation are critical for axon guidance (Campbell and Holt, 2001). Moreover, axons can use multiple guidance mechanisms including axon fasciculation or gradients of signaling factors to navigate to their targets (Dickson, 2002). In the case of LMC(1) neurons, ephrin-A5 is inhibitory to axon advance, interacting with EphA4 receptors known to be present on LMC(l) growth cones (Eberhart et al., 2000; this study). In the case of $\mathrm{MMC}(\mathrm{m})$ neurons, ephrin-A5 would interact with EphA4 localized primarily to the surfaces of axon shafts, presumably influencing axon fasciculation. Experiments are in progress to examine the underlying cell biology of EphA4ephrin-A5 signaling in these motor neuron populations.

Notably, there are distinct effects of premature or ectopic expression of EphA4 on $\mathrm{MMC}(\mathrm{m})$ and $\mathrm{LMC}(\mathrm{m})$ neurons, respectively. Here, we show that $27 \%$ of $\mathrm{MMC}(\mathrm{m})$ neurons extend their axons into novel ephrin-A5 territories in the dorsal neural tube or DRG when EphA4 was prematurely expressed. In contrast, 76\% of $\mathrm{LMC}(\mathrm{m})$ neurons that ectopically expressed EphA4 grew aberrantly into the dorsal nerve trunk of the crural plexus in the hindlimb, instead of their normal ventral trajectory, but never exited the hindlimb (Eberhart et al., 2002). Furthermore, $\mathrm{LMC}(\mathrm{m})$ axons that ectopically expressed EphA4 did not extend 
into ephrin-A5-rich territories. Together, these results suggest that EphA4 does not act as a molecular switch to determine whether motor axons will enter the hindlimb to innervate limb muscle or the dorsal ramus to innervate epaxial muscle. Instead, EphA4-positive MMC(m) and LMC neurons exhibit distinct responses to ephrin-A5.

It is conceivable that $\mathrm{LMC}(\mathrm{l})$ and $\mathrm{MMC}(\mathrm{m})$ neurons respond differently to ephrin-A5 in our experiments because of dissimilarities in ephrin-A5 protein concentrations that influence cell behavior differently. However, this does not appear to be the case: the same ephrin-A5/EGFP plasmid concentration was used in all in ovo manipulations, generating comparable levels of cell transfection. Furthermore, isolated $\mathrm{LMC}(\mathrm{l})$ and $\mathrm{MMC}(\mathrm{m})$ neurons respond distinctly to identical concentrations of substrate-bound ephrin-A5. It remains possible that the signaling components downstream of ephrin-A5 are distinct in hindlimb mesoderm and the somitic sclerotome. Other studies have argued that the axonal coexpression of an Eph receptor and ephrin dampens the inhibitory or repellent effects of ephrins located in the target tissue (Hornberger et al., 1999). This mechanism is not likely to account for the differential responses to ephrin-A5 observed here. Axons of LMC(1) neurons are decorated with EphA4 and ephrin-A2 protein (Eberhart et al., 2000) and yet are inhibited from entering ephrin-A5-positive domains in target limb mesoderm. With regard to $\mathrm{MMC}(\mathrm{m})$ neurons, we have not detected ephrins on these axons (J. Eberhart and C. E. Krull, unpublished data).

Results of previous studies suggest that ephrin-A5 can influence axon projections and growth in a positive manner. Ephrin-A5 promotes branch formation in thalamic axons (Mann et al., 2002) and enhances the process outgrowth of cortical neurons (Zhou et al., 2001). Growing axons can alter their responsiveness to extracellular cues that are encountered during navigation to their targets. Another Eph family member, ephrin-B1, can act bifunctionally, serving as a repellent and an attractant for retinal ganglion cell axons (McLaughlin et al., 2003) and for different populations of neural crest cells (Santiago and Erickson, 2002). Our data support the view that EphA4-ephrin-A5 interactions can be either inhibitory or positive for motor neurons based on the subcellular localization of their signaling machinery. Intriguingly, these data suggest the existence of distinct EphA4 signaling cascades in these neuron subpopulations. Using these strategies, Eph receptors and ephrins could indeed exert multiple influences on the patterning of axonal projections and other developmental processes.

\section{References}

Brittis PA, Qiang L, Flanagan JG (2002) Axonal protein synthesis provides a mechanism for localized regulation at an intermediate target. Cell 110:223-235.

Campbell DS, Holt CE (2001) Chemotropic responses of retinal growth cones mediated by rapid local protein synthesis and degradation. Neuron 32:1013-1026.

Dickson BJ (2002) Molecular mechanisms of axon guidance. Science 298:1959-1964.

Eberhart J, Swartz M, Koblar SA, Pasquale EB, Tanaka H, Krull CE (2000) Expression of EphA4, ephrin-A2 and ephrin-A5 during axon outgrowth to the hindlimb indicates potential roles in pathfinding. Dev Neurosci 22:237-250.

Eberhart J, Swartz ME, Koblar SA, Pasquale EB, Krull CE (2002) EphA4 constitutes a population-specific guidance cue for motor neurons. Dev Biol 247:89-101.

Ensini M, Tsuchida TN, Belting HG, Jessell TM (1988) The control of rostrocaudal pattern in the developing spinal cord: specification of motor neuron subtype identity is initiated by signals from paraxial mesoderm. Development 125:969-982.
Ethell IM, Irie F, Kalo MS, Couchman JR, Pasquale EB, Yamaguchi Y (2001) EphB/syndecan-2 signaling in dendritic spine morphogenesis. Neuron 31:1001-1013.

Fukushima M, Nakamura M, Ohta K, Okamura R, Negi A, Tanaka H (1996) Regional specification of motoneurons along the anterior-posterior axis is independent of the notochord. Development 122:905-914.

Gale NW, Holland SJ, Valenzuela DM, Flenniken A, Pan L, Ryan TE, Henkemeyer M, Strebhardt K, Hirai H, Wilkinson DG, Pawson T, Davis S, Yancopoulos GD (1996) Eph receptors and ligands comprise two major specificity subclasses and are reciprocally compartmentalized during embryogenesis. Neuron 17:9-19.

Hamburger V, Hamilton HL (1951) A series of normal stages in the development of the chick embryo. J Morphol 88:49-92.

Helmbacher F, Schneider-Maunoury S, Topilko P, Tiret L, Charnay P (2000) Targeting of the EphA4 tyrosine kinase receptor affects dorsal/ventral pathfinding of limb motor axons. Development 127:3313-3324.

Hornberger MR, Dutting D, Ciossek T, Yamada T, Handwerker C, Lang S, Weth F, Huf J, Wessel R, Logan C, Tanaka H, Drescher U (1999) Modulation of EphA receptor function by coexpressed ephrinA ligands on retinal ganglion cell axons. Neuron 22:731-742.

Kania A, Jessell TM (2003) Topographic motor projections in the limb imposed by LIM homeodomain protein regulation of ephrin-A:EphA interactions. Neuron 38:581-596.

Kania A, Johnson RL, Jessell TM (2000) Coordinate roles for LIM homeobox genes in directing the dorsoventral trajectory of motor axons in the vertebrate limb. Cell 102:161-173.

Keleman K, Rajagopalan S, Cleppien D, Teis D, Paiha K, Huber LA, Technau GM, Dickson BJ (2002) Comm sorts robo to control axon guidance at the Drosophila midline. Cell 110:415-427.

Kilpatrick TJ, Brown A, Lai C, Gassman M, Goulding M, Lemke G (1996) Expression of the Tyro4/Mek4/Cek4 gene specifically marks a subset of embryonic motor neurons and their muscle targets. Mol Cell Neurosci 7:62-74.

Knoll B, Zarbalis K, Wurst W, Drescher U (2001) A role for the EphA family in the topographic targeting of vomeronasal axons. Development 128:895-906.

Koblar SA, Krull CE, Pasquale EB, McLennan R, Peale FD, Cerretti DP, Bothwell M (2000) Spinal motor axons and neural crest cells use different molecular guides for segmental migration through the rostral halfsomite. J Neurobiol 42:437-447.

Krull CE (2004) A primer on using in ovo electroporation to analyze gene function. Dev Dyn, in press.

Kullander K, Klein R (2002) Mechanisms and functions of Eph and ephrin signaling. Nat Rev Mol Cell Biol 3:475-486.

Lance-Jones C, Landmesser LT (1980) Motoneuron projection patterns in the chick hind limb following early partial reversals of the spinal cord. J Physiol (Lond) 302:581-602.

Lance-Jones C, Landmesser LT (1981) Pathway selection by embryonic chick motoneurons in an experimentally altered environment. Proc R Soc Lond B Biol Sci 214:19-52.

Landmesser L (1978) The development of motor projection patterns in the chick hind limb. J Physiol (Lond) 284:391-414.

Lee VM, Carden MJ, Schlaepfer WW, Trojanowski JQ (1987) Monoclonal antibodies distinguish several differentially phosphorylated states of the two largest rat neurofilament subunits (NF-H and NF-M) and demonstrate their existence in the normal nervous system of adult rats. J Neurosci 7:3474-3488.

Mann F, Peuckert C, Dehner F, Zhou R, Bolz J (2002) Ephrins regulate the formation of terminal axonal arbors during the development of thalamocortical projections. Development 129:3945-3955.

McLaughlin T, Hindges R, Yates PA, O'Leary DD (2003) Bifunctional action of ephrin-B1 as a repellent and attractant to control bi-directional branch extension in dorsal-ventral retinotopic mapping. Development 130:2407-2418

Ohta K, Nakamura M, Hirokawa K, Tanaka S, Iwama A, Suda T, Ando M, Tanaka H (1996) The receptor tyrosine kinase Cek8 is transiently expressed on subtypes of motoneurons in the spinal cord during development. Mech Dev 54:59-69.

Osumi N, Inoue T (2001) Gene transfer into cultured mammalian embryos by electroporation. Methods 24:35-42.

Santiago A, Erickson CA (2002) Ephrin-B ligands play a dual role in the control of neural crest cell migration. Development 129:3621-3632. 
Shamah SM, Lin MZ, Goldberg JL, Estrach S, Sahin M, Hu L, Bazalakova M, Neve RL, Corfas G, Debant A, Greenberg ME (2001) EphA receptorsregulate growth cone dynamics through the novel guanine nucleotide exchange factor ephexin. Cell 105:233-244.

Sharma K, Sheng HZ, Lettieri K, Li H, Karavanov A, Potter S, Westphal H, Pfaff SL (1998) LIM homeodomain factors Lhx3 and Lhx4 assign subtype identities for motor neurons. Cell 95:817-828.

Sharma K, Leonard AE, Lettieri K, Pfaff SL (2000) Genetic and epigenetic mechanisms contribute to motor neuron pathfinding. Nature 406:515-519.

Soans C, Holash JA, Pasquale EB (1994) Characterization of the expression of the Cek8 receptor-type tyrosine kinase during development and in tumor cell lines. Oncogene 9:3353-3361.

Swartz M, Eberhart J, Mastick G, Krull CE (2001a) Sparking new frontiers: using in vivo electroporation for genetic manipulations. Dev Biol 233:13-21.

Swartz ME, Eberhart J, Pasquale EB, Krull CE (2001b) EphA4/ephrin-A5 interactions in muscle precursor cell migration in the avian forelimb. Development 128:4669-4680.
Summerbell D, Stirling RV (1981) The innervation of dorso-ventrally reversed chick wings: evidence that motor axons do not actively seek out their appropriate targets. Exp Morphol 61:233-247.

Tosney KW (1987) Proximal tissues and patterned neurite outgrowth at the lumbosacral level of the chick embryo: deletion of the dermomyotome. Dev Biol 122:540-548.

Tosney KW, Landmesser LT (1985) Growth cone morphology and trajectory in the lumbosacral region of the chick embryo. J Neurosci 5:2345-2358.

Tsuchida T, Ensini M, Morton SB, Baldassare M, Edlund T, Jessell TM, Pfaff SL (1994) Topographic organization of embryonic motor neurons defined by expression of LIM homeobox genes. Cell 79:957-970.

Whitelaw V, Hollyday M (1983) Neural pathway constraints in the motor innervation of the chick hindlimb following dorsoventral rotations of distal limb segments. J Neurosci 3:1226-1233.

Zhou X, Suh J, Cerretti DP, Zhou R, DiCicco-Bloom E (2001) Ephrins stimulate neurite outgrowth during early cortical neurogenesis. J Neurosci Res 66:1054-1063. 